\title{
Chapter 15 \\ Research on the Correlation Between \\ Chlorophyll-a and Organic Matter BOD, \\ COD, Phosphorus, and Total Nitrogen \\ in Stagnant Lake Basins
}

\author{
Song Toan Pham Phu
}

\begin{abstract}
We are frequently required to assess, mitigate, and monitor certain environmental risks involved in our daily activities at both the local and global environment levels. Corporations, in particular, can cause environmental pollution or other risks as a result of either accidents or natural events. In order to limit, and hopefully prevent, these environmental impacts, environmental risk management places a strong emphasis on targeting the problems that could arise, and implements a system of metrics that help with prevention and management. Eutrophication is one example of a widespread environmental pollution phenomenon that is currently worsening in lake basins. Proliferation of phytoplankton is due primarily to high concentrations of nitrogen $(\mathrm{N})$ and phosphorus $(\mathrm{P})$ discharged from industrial and urban waste. However, assessing, managing, and forecasting the pollution of basins requires considerable time and support tools to analyze a range of water quality indicators over time and geographical area. This study investigated the relationship between organic matter (chemical oxygen demand, biochemical oxygen demand, total N, and P) and biomass of phytoplankton (indicated by Chlorophyll-a) in order to shorten the period required for analysis, predict eutrophication of lakes ahead of time, and promptly prevent the spread of contaminants. Based on this relationship, we can use Chlorophyll-a as a biological indicator in monitoring and assessing the levels of organic pollution. In addition, we can identify ways to reduce pollution and transportation of pollutants in stagnant lake basins, and contribute to reducing the damage due to environmental risks.
\end{abstract}

Keywords Chlorophyll-a • Environmental risk management • Eutrophication • Organic pollutants $\bullet$ Phytoplankton

S.T.P. Phu $(\bowtie)$

The University of Da Nang, Da Nang, Vietnam

e-mail: ppstoan@gmail.com 


\subsection{Introduction}

Water pollution is a problem of concern all over the world and it involves difficult issues relating to water management and environmental protection. It not only affects a large water surface and destroys aquatic communities, but also impacts on human health and quality of life. In developing countries nowadays, the consequences of industrial development and urban population growth involve issues of water pollution, leading especially to pollution of foodstuffs. This raises the urgent need for a monitoring program with specific early warning targets to enable measures to be taken to prevent pollution in a timely manner.

Eutrophication is a natural process that has been occurring for thousands of years. Its speed has increased rapidly in recent decades due to human activities. Eutrophication involves an increase in nutrients (especially nitrogen and phosphorus) in water, causing excessive growth of the lower species of plants such as algae. It creates major changes in aquatic ecosystems, causing deterioration of water quality. The biochemical basis of the eutrophication process is photochemical reaction, which increases phytoplankton biomass (Fig. 15.1).

There are many indicators to assess water quality including physical, chemical, and biological indicators. Phytoplankton in particular are considered to be an evaluation parameter for organic pollution. Chlorophyll, meanwhile, has long been known as a major pigment with the role of absorbing solar radiation energy as part of the optical response of plant biomass. Therefore, assessment of phytoplankton biomass through chlorophyll analysis requires a combination of chemical and biological methods. From chlorophyll concentration we can establish the relationship between chlorophyll and other pollution parameters to be able to quickly assess the status of eutrophication and organic pollution in a lake basin. Thus we can evaluate water quality through chlorophyll indicators.

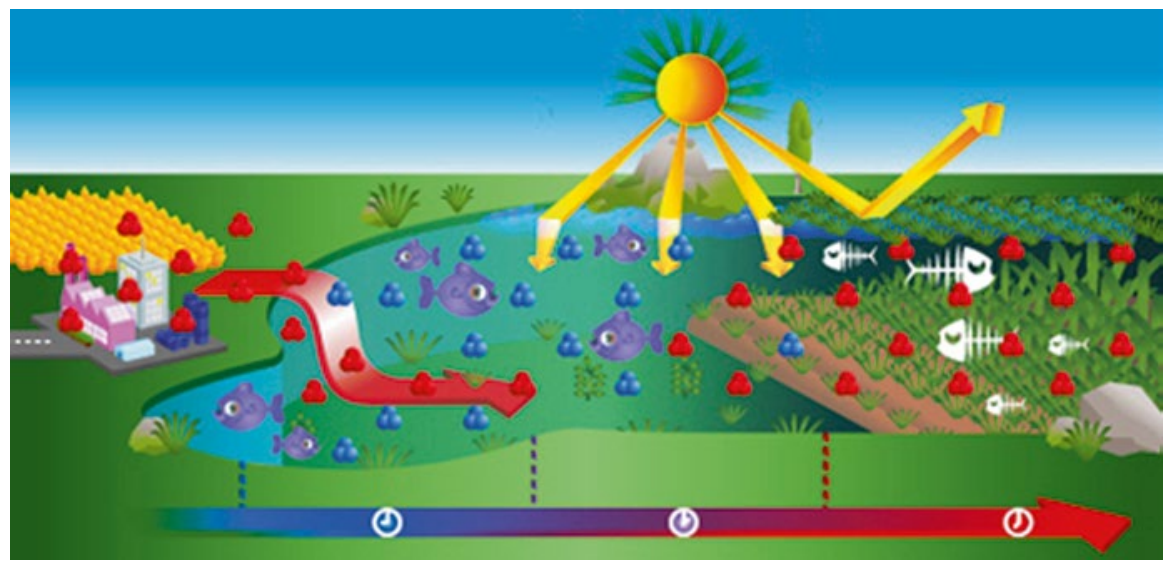

Fig. 15.1 The eutrophication process (Source: www.renault.com) 
Table 15.1 OECD

classification of nutrients in lakes

\begin{tabular}{lll}
\hline Condition of lake & Chl-a $\left(\mathrm{mg} / \mathrm{m}^{3}\right)$ & Chl- $\mathrm{a}_{\max }\left(\mathrm{mg} / \mathrm{m}^{3}\right)$ \\
\hline Lack of nutrients & $<1$ & $<2.5$ \\
Poor nutrients & $<2.5$ & $<8.0$ \\
Average nutrients & $2.5-8.0$ & $8.0-25.0$ \\
Eutrophication & $8.0-25.0$ & $25.0-75.0$ \\
Super eutrophication & $>25$ & $>75$
\end{tabular}

Source: OECD-Organization for Economic Co-operation and Development

The role of phytoplankton in nutrient-rich freshwater is large. They provide oxygen for aerobic organisms, disintegrate organic compounds, and remove minerals and other nutrients from the environment. But when excessive growth of phytoplankton occurs, algal blooms reduce the decomposition of algae in the sediment and lead to the destruction of water ecosystems.

There are many methods of assessing phytoplankton biomass, including:

- Calculating individual density combined with measuring average individual volume of all species;

- Measuring the weight of all individuals in a unit volume;

- Measuring carbon concentration derived from organic matter;

- Measuring the pigment concentration;

- Measuring the rate of exchange of oxygen and carbon dioxide;

- Measuring adenosine triphosphate (ATP).

Of the above, measuring pigment concentration is the most viable method. The photosynthetic reaction of phytoplankton generates biomass, which can therefore be assessed just by determining the pigment concentration. This differs from the other parameters above that are integrated in the metabolism of phytoplankton. Therefore analysis of Chlorophyll-a (Chl-a) is a good means of estimating the nutritional status of a lake. This method is simpler, faster, and more economical than estimating phytoplankton biomass by microscopy. Thus Chl-a concentration can determine the level of lake eutrophication (Table 15.1).

\subsection{Subjects of Study}

\subsubsection{Chlorophyll}

Chlorophyll is the common name of a plant pigment capable of absorbing solar energy for the process of plant photosynthesis. Within plant cells, chlorophyll is organized distinctively, distributed in cytoplasm called chloroplasts. The molecular structure of chlorophyll comprises two parts: the porphyrin ring and the phytol (an 


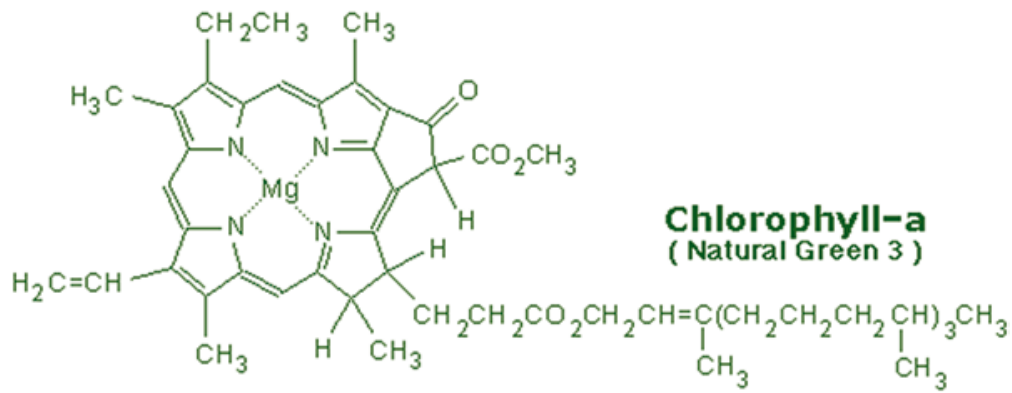

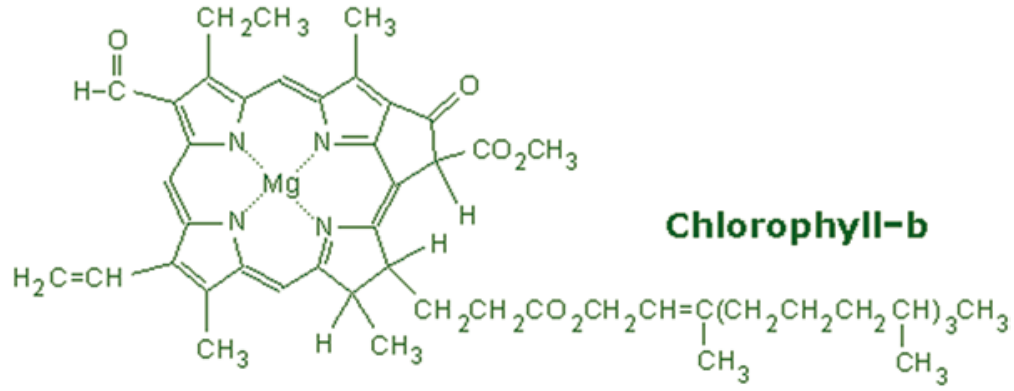

Fig. 15.2 Structure of Chlorophyll-a and Chlorophyll-b (Source: www.ysi.com)

acyclic hydrocarbon). The porphyrin ring is a strong chelating ligand created when four $\mathrm{N}$ atoms strongly associated with a metal atom $(\mathrm{Mg})$ are coordinated in a planar arrangement (Fig. 15.2).

In nature, the two most common forms of chlorophyll are Chlorophyll-a $\left(\mathrm{C}_{55} \mathrm{H}_{72} \mathrm{O}_{5} \mathrm{~N}_{4} \mathrm{Mg}\right)$ and Chlorophyll-b $\left(\mathrm{C}_{55} \mathrm{H}_{70} \mathrm{O}_{6} \mathrm{~N}_{4} \mathrm{Mg}\right)$ with a ratio of Chlorophyll-a to Chlorophyll-b of $3: 1$.

There are several methods to determine chlorophyll:

- UV-vis photometry

- Fluorescence measuring

- High Pressure Liquid Chromatography (HPLC)

- Use of remote sensing images

\subsubsection{BOD: Biochemical Oxygen Demand}

BOD is the amount of oxygen demand for microorganisms to oxidate and stabilize dissolved organic or inorganic substances in water under certain conditions. Bacteria use dissolved oxygen (DO) for decomposition of organic matter and as a result DO will be reduced. 
The oxidation of organic matter in water can occur in two phases:

- The first phase is mainly oxidation of hydrocarbon (HC). This phase occurs for 20 days at $20^{\circ} \mathrm{C}$

$$
\mathrm{HC}+\mathrm{O}_{2}+\text { Microorganism } \rightarrow \mathrm{CO}_{2}+\mathrm{H}_{2} \mathrm{O}
$$

- The second phase is oxidation of nitrogen-containing compounds. This phase starts from the tenth day (or can start as early as the fifth day).

$$
\begin{gathered}
2 \mathrm{NH}_{3}+\mathrm{O}_{2}+\text { Microorganism } \rightarrow 2 \mathrm{NO}_{2^{-}}+2 \mathrm{H}^{+}+2 \mathrm{H}_{2} \mathrm{O} \\
2 \mathrm{NO}_{2^{-}}+\mathrm{O}_{2}+\text { Microorganism } \rightarrow 2 \mathrm{NO}_{3^{-}}
\end{gathered}
$$

BOD is the single most important parameter to assess water pollution. The higher the BOD concentration, the more biodegradable organic matter exists. A typical concentration might be " $\mathrm{BOD}_{5}$ " which is oxygen demand to oxidate biodegradable organic matter at $20^{\circ} \mathrm{C}$ for 5 days.

\subsubsection{COD: Chemical Oxygen Demand}

COD is the amount of oxygen demand to oxidate organic matter fully in water. It is a parameter for both organic matter easily susceptible to biodegradation and organic matter that resists biodegradation. Thus, COD is determined by the photometric method with strong oxidizing reagents in an acid environment and involvement of $\mathrm{Ag}_{2} \mathrm{SO}_{4}$ as a catalyst.

$$
\begin{aligned}
& \mathrm{C}_{\mathrm{n}} \mathrm{H}_{\mathrm{a}} \mathrm{O}_{\mathrm{b}} \mathrm{N}_{\mathrm{c}}+\mathrm{dCr}_{2} \mathrm{O}_{7}^{2-}+(8 \mathrm{~d}+\mathrm{c}) \mathrm{H}^{+} \\
& \quad\left(\mathrm{Ag}_{2} \mathrm{SO}_{4}\right) \rightarrow \mathrm{nCO}_{2}+(\mathrm{a}+8 \mathrm{~d}-3 \mathrm{c}) / 2 \mathrm{H}_{2} \mathrm{O}+\mathrm{c} \mathrm{NH} \mathrm{NH}^{4+}+2 \mathrm{dCr}^{3+}
\end{aligned}
$$

This method allows COD to be determined from 10-500 mg/L in $2 \mathrm{~h}$.

\subsubsection{Phosphorus}

Phosphorus exists in water in many forms: ortho phosphate $\left(\mathrm{PO}_{4}{ }^{3-}\right)$, polyphosphate $\left(\mathrm{P}_{2} \mathrm{O}_{7}^{4-}, \mathrm{P}_{3} \mathrm{O}_{10}{ }^{5-}\right)$ and organic phosphorus. In addition, bio-inorganic and organic phosphorus is found in sediment and sludge. Phosphorus is one of the nutritional components necessary for the life of organisms, especially aquatic life.

Ortho phosphate is determined by the photometric method with a vanadate molybdate reagent.

$$
\mathrm{PO}_{4}{ }^{3-}+\mathrm{VO}_{3^{-}}+11 \mathrm{MoO}_{4}{ }^{2-}+25 \mathrm{H}^{+} \rightarrow \mathrm{H}^{3} \mathrm{PVMo}_{11} \mathrm{O}_{40}+11 \mathrm{H}_{2} \mathrm{O}
$$




\subsubsection{Nitrogen}

Nitrogen exists in water in several forms:

- Ammonium $\left(\mathrm{NH}_{4}^{+}\right)$: The metabolic product of nitrogen-containing compounds in wastewater.

$$
\mathrm{NH}_{3}+\mathrm{H}^{+} \rightarrow \mathrm{NH}_{4}^{+}
$$

- Nitrate $\left(\mathrm{NO}_{3}{ }^{-}\right)$: In a low $\mathrm{pH}$ environment, $\mathrm{NH}_{3}$ is metabolized to $\mathrm{NH}_{4}{ }^{+}$and oxidized to $\mathrm{NO}_{3}{ }^{-}$by oxygen.

$$
\mathrm{NH}_{4}^{+}+2 \mathrm{O}_{2} \rightarrow \mathrm{H}_{2} \mathrm{O}+2 \mathrm{H}^{+}
$$

- Nitrite $\left(\mathrm{NO}_{2}^{-}\right)$The intermediate product of the nitrogen cycle, nitrite is toxic to fish and other aquatic life.

Determination of nitrogen is based on the principle of oxidizing samples to produce the ammonium form of nitrogen.

$$
\begin{gathered}
\mathrm{NH}_{4}^{+}+\mathrm{OH}^{-} \rightarrow \mathrm{NH}_{3}+\mathrm{H}_{2} \mathrm{O} \\
\mathrm{HBO}_{2}+\mathrm{NH}_{3}=\mathrm{NH}_{4}^{+}+\mathrm{BO}_{2}
\end{gathered}
$$

Ammonium is determined using titrate $\mathrm{BO}_{2}-$ with $\mathrm{HCl} 0.01 \mathrm{~N}$ :

$$
\mathrm{BO}_{2^{-}}+\mathrm{H}^{+}+=\mathrm{HBO}_{2}
$$

\subsection{Research Methodology}

\subsubsection{Determination of Chlorophyll}

\subsubsection{Chlorophyll Refining}

The chlorophyll refining process is as shown in Fig. 15.3. Chl-a was extracted from bamboo leaf in $3 \mathrm{~h}$ using the Soxhlet system with acetone as the solvent. The products obtained were evaporated to remove the solvent and Chl-a was tested for purity using plate chromatography with an ultraviolet light wavelength of $254 \mathrm{~nm}$. 


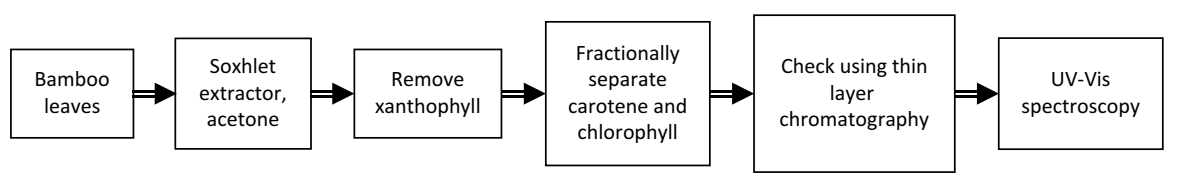

Fig. 15.3 The chlorophyll refining process

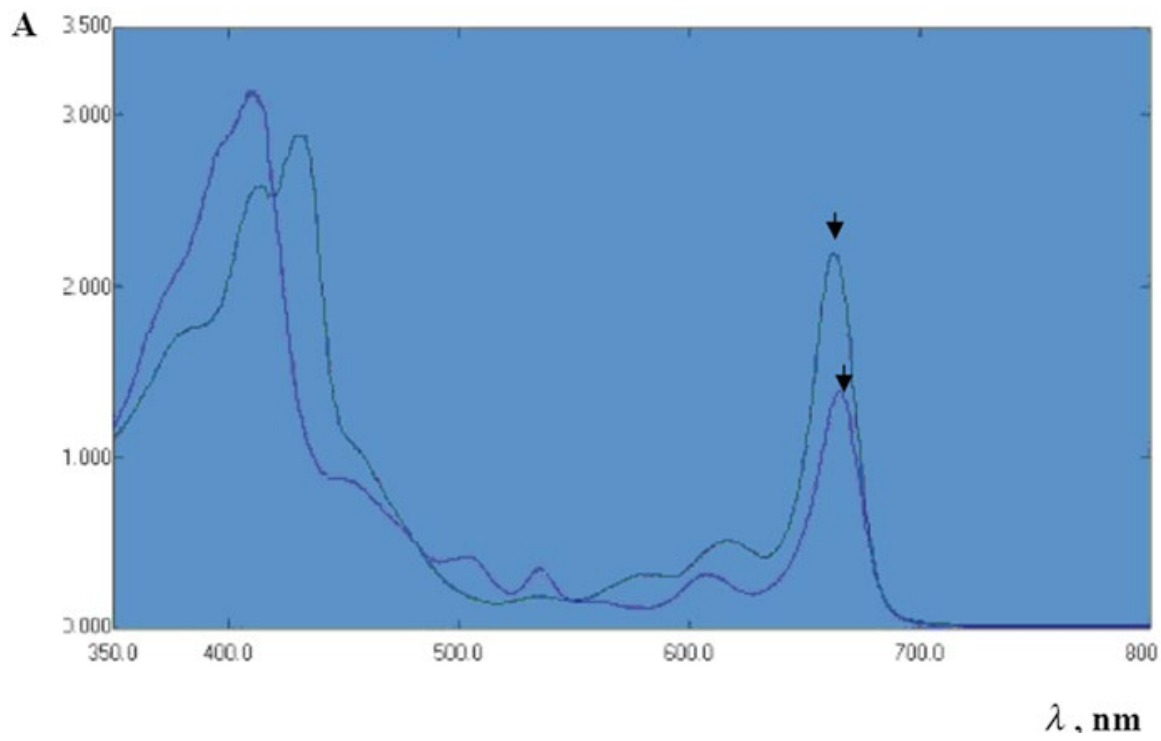

Fig. 15.4 UV-vis absorption spectra of Chl-a (top) and pheophytin-a (bottom)

\subsubsection{Determining the Maximum Absorption of Chl-a}

Refined chlorophyll was dissolved in acetone. The resulting liquid was measured using UV-vis spectroscopy. Spectrometric results showed that the maximum absorption in the visible region corresponded to wavelengths of 664 and $665 \mathrm{~nm}$ for pheophytin-a and Chl-a (Fig. 15.4). Thus, a $664 \mathrm{~nm}$ wavelength was chosen to measure the absorbance in the determination process.

\subsubsection{Building a Chl-a Calibration Curve}

Dissolve purified chlorophyll in a mixture of $90 \%$ acetone and $10 \%$ saturated $\mathrm{MgCO}_{3}$ and prepare norms of standard volume at a concentration of $100,000 \mathrm{~g} / \mathrm{L}$.

Dilute the working Chl-a liquid at a concentration of 5,000 $\mu \mathrm{g} / \mathrm{L}$.

Build the ranges of standard fluids from the working Chl-a and measure absorbance at a wavelength of maximum absorbance of Chl-a: $\lambda=664 \mathrm{~nm}$ Fig. 15.5 depicts the calibration curve of Chl-a in chart form. 


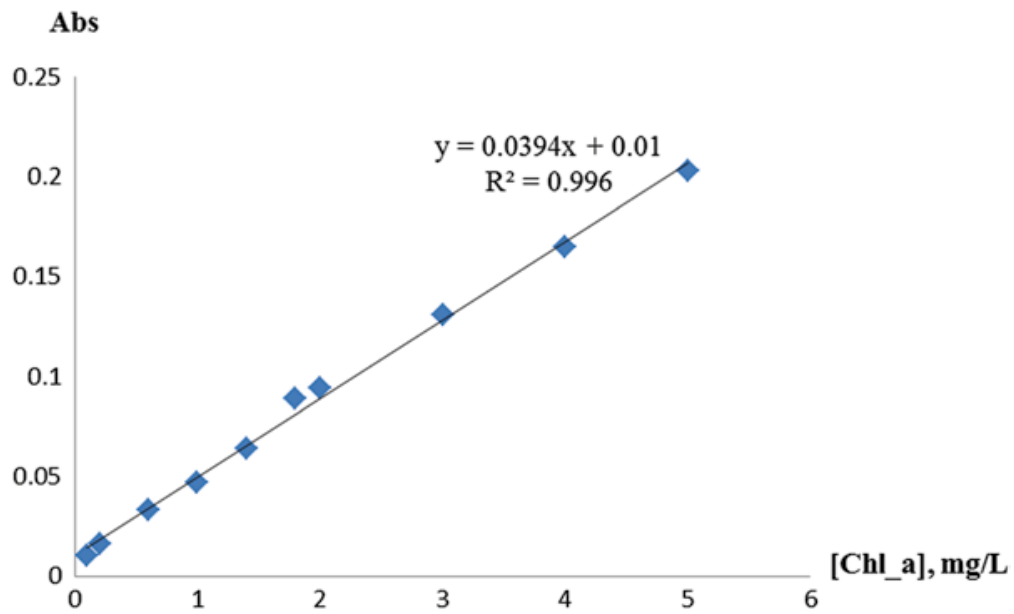

Fig. 15.5 Calibration curve of chlorophyll-a

\subsubsection{Determination of $\mathrm{BOD}_{5}$}

Prepare dilutions:

- Put $\mathrm{V}_{\mathrm{d}}(\mathrm{mL})$ sample into BOD bottle

- Control $\mathrm{pH}$ at around 7

- Add enough V (mL) dilution liquid to fill BOD bottle

- Measure DO $_{\mathrm{i}}$ using DO meter

- Cap BOD bottle and put in BOD cabinet at $20{ }^{\circ} \mathrm{C}$ for 5 days

- Measure $\mathrm{DO}_{\mathrm{f}}$ by DO meter after 5 days

$\mathrm{BOD}_{5}$ can be calculated using the following formula:

$$
\mathrm{BOD}_{5}=\frac{\left(\mathrm{DO}_{\mathrm{i}}-\mathrm{DO}_{\mathrm{f}}\right) \cdot \mathrm{V}_{\mathrm{d}}}{\mathrm{V}_{\mathrm{s}}}
$$

where $\mathrm{DO}_{\mathrm{i}}$ is the amount of dissolved oxygen in the diluted sample; $\mathrm{DO}_{\mathrm{f}}$ is the dissolved oxygen content of the sample after 5 days of incubation at $20{ }^{\circ} \mathrm{C} ; \mathrm{V}_{\mathrm{d}}$ is the volume of the sample after diluting; $\mathrm{V}_{\mathrm{s}}$ is the volume of the sample before diluting. 


\subsubsection{Determination of COD}

\subsubsection{Building a COD Calibration curve}

- Prepare standard fluids; mix standard fluids at concentrations of:

$$
\begin{array}{lllllllll}
10 & 20 & 40 & 60 & 80 & 100 & 120 & 140 & (\mathrm{mg} / \mathrm{L})
\end{array}
$$

- Put exact volumes of standard fluids into the ampoules: (Table 15.2)

- Shake ampoules well, dry them, and put them into the heating machine at $150{ }^{\circ} \mathrm{C}$ for $120 \mathrm{~min}$

- Centrifuge at a speed of 3,000 cycles/15 min

- Do the same for the fresh sample using $2.5 \mathrm{~mL}$ of distilled water instead of the standard fluid

Figure 15.6 depicts the calibration curve of COD in chart form.

Table 15.2 Volumes of standard fluids in ampoules

\begin{tabular}{lll}
\hline Number & Fluids & $\mathrm{V}(\mathrm{mL})$ \\
\hline 1 & Sample & 2.5 \\
2 & $\mathrm{~K}_{2} \mathrm{Cr}_{2} \mathrm{O}_{7}$ & 1.5 \\
3 & $\mathrm{Ag}_{2} \mathrm{SO}_{4}$ & 3.5 \\
\hline
\end{tabular}

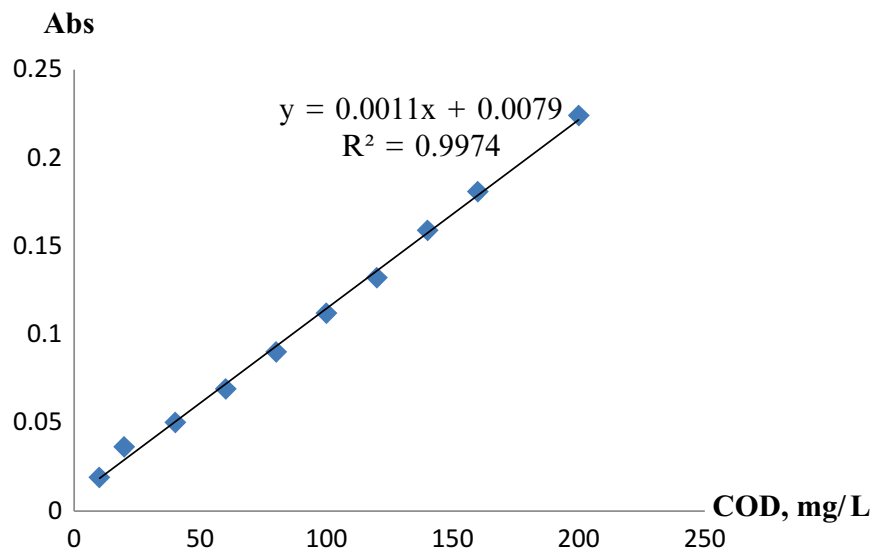

Fig. 15.6 Calibration curve of COD 


\subsubsection{Determination of Phosphate}

Building a phosphate calibration curve:

- Prepare standard fluids; mix standard fluids with $\mathrm{PO}_{3}{ }^{4-}$ concentrations of:

$$
\begin{array}{llllllll}
0 & 0.4 & 2.0 & 4.0 & 6.0 & 8.0 & 10.0 & (\mathrm{mg} / \mathrm{L})
\end{array}
$$

- Put $5.0 \mathrm{~mL}$ vanadate-molybdate into each bottle of fluid; norms to be $50 \mathrm{~mL}$ by distilled water; shake thoroughly

- Wait for $10 \mathrm{~min}$ at room temperature; measure the absorbance at $400 \mathrm{~nm}$ wavelengths

A calibration curve can be built in the same way as for COD.

\subsection{Results}

\subsubsection{Correlation Between Chl-a and COD}

The research subjects were Ham Nghi Lake and March 29 Park Lake, both located in the city of Danang (Figs. 15.7 and 15.8). The study period was from March to May 2013 (the dry season).

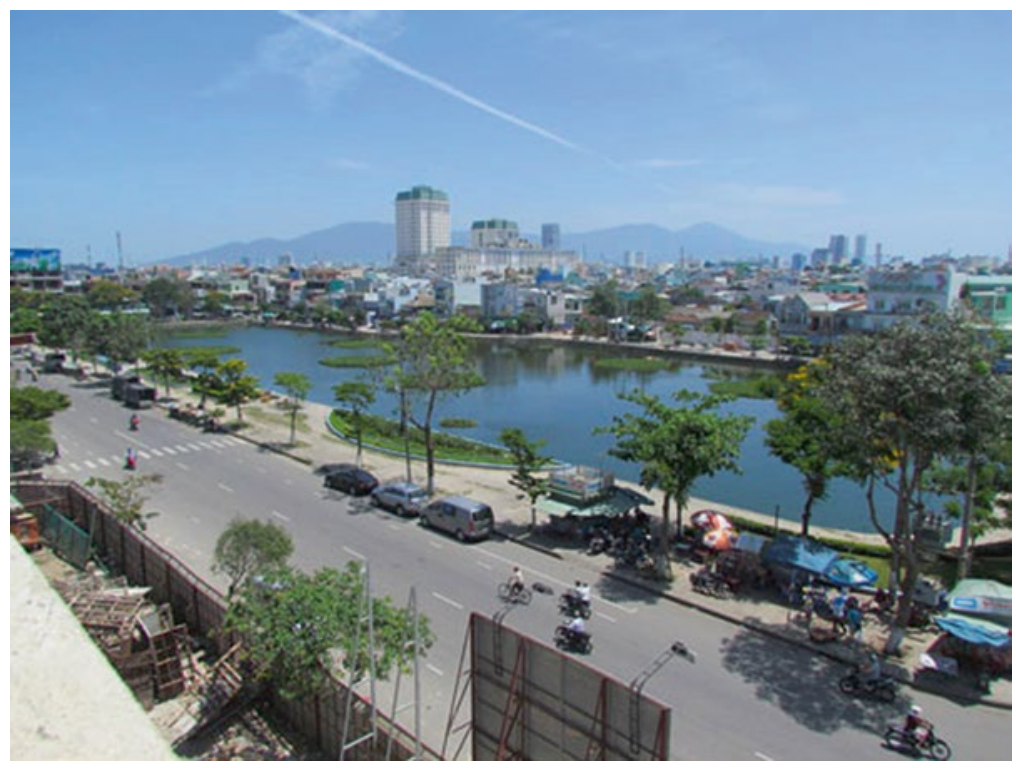

Fig. 15.7 Ham Nghi Lake (Source: http://rongbay.com/Da-Nang/) 


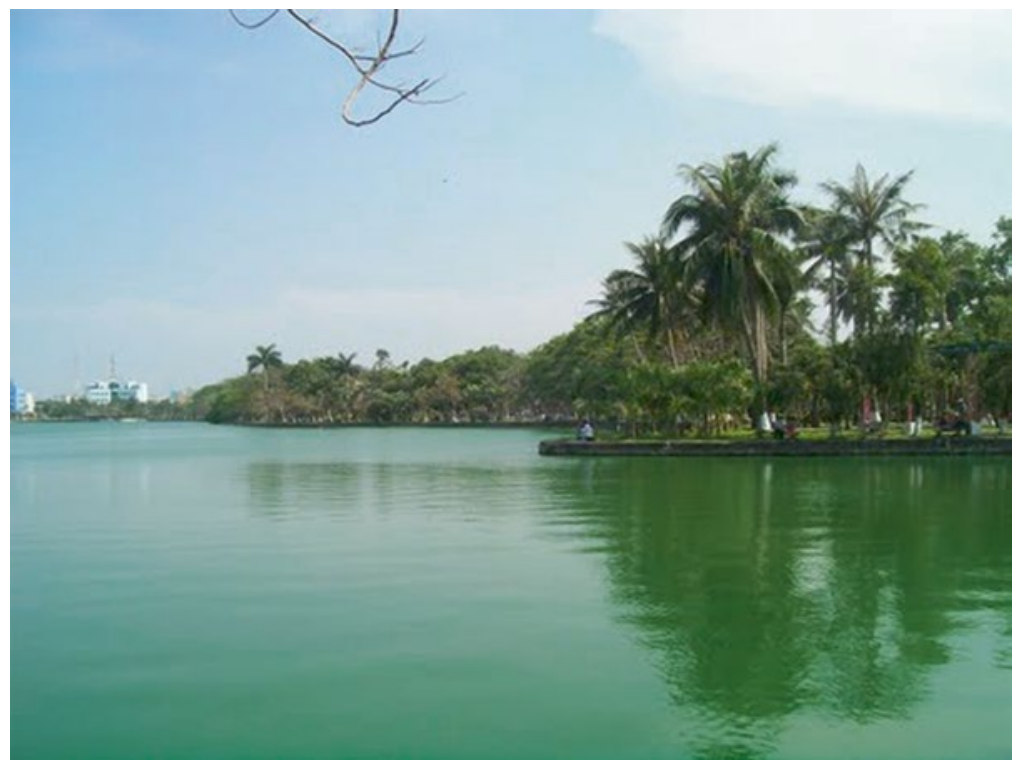

Fig. 15.8 March 29 Park Lake (Source: http://wikimapia.org/4681749/)

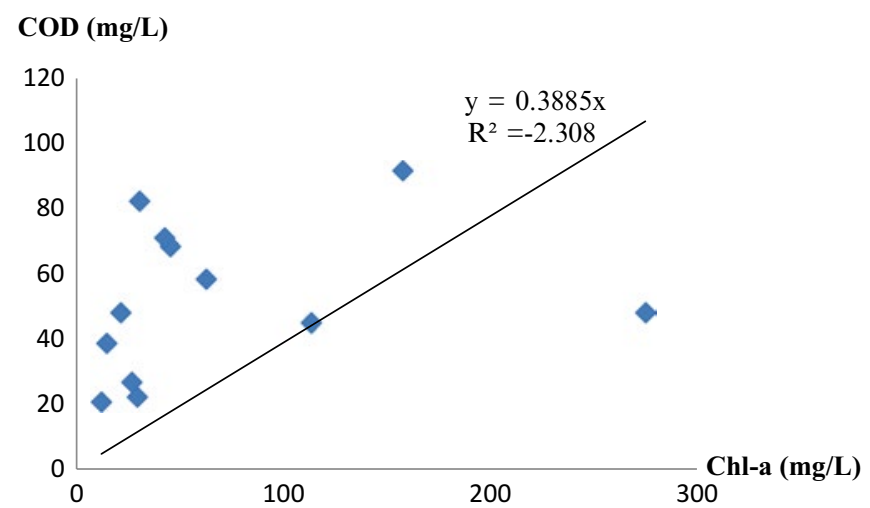

Fig. 15.9 Correlation between Chl-a and COD in Ham Nghi Lake

By comparing the results for COD and Chl-a, we can assess the correlation between them (Figs. 15.9 and 15.10). No correlation was identified between the concentrations of Chl-a and COD. This was because COD (chemical oxygen demand) is a pollution parameter for all components including organic compounds that resist biodegradation. The growth of phytoplankton is related only to organic pollution. 


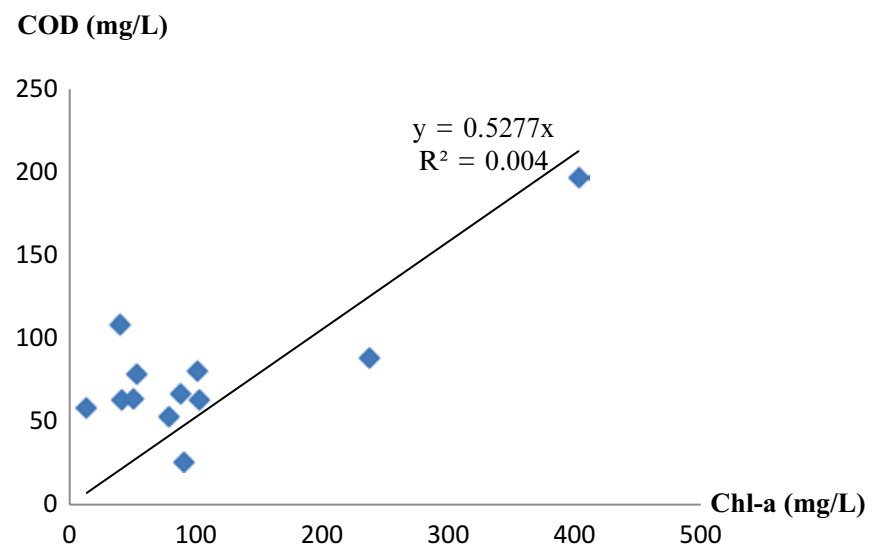

Fig. 15.10 Correlation between Chl-a and COD in March 29 Park Lake

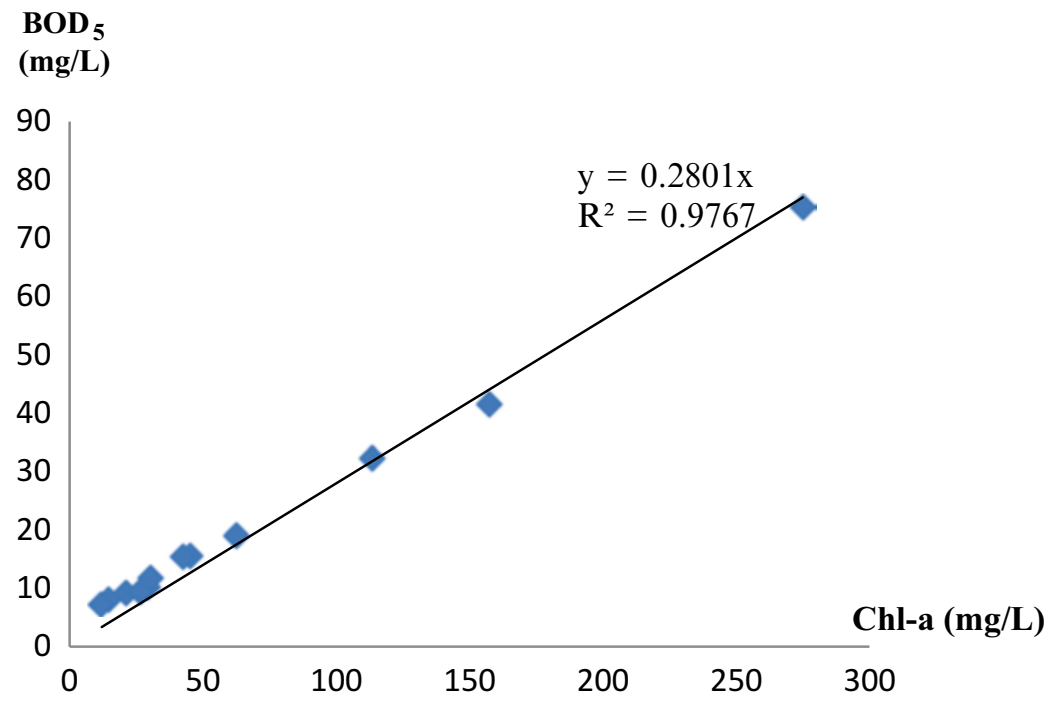

Fig. 15.11 Correlation between Chl-a and BOD in Ham Nghi Lake

\subsubsection{Correlation Between Chl-a and BOD}

BOD was analyzed at the same time as COD. The BOD analysis results are shown in Figs. 15.11 and 15.12.

We can see that BOD and Chl-a have a clear correlation with a reliable linear gain coefficient of $\mathrm{R}^{2}>0.95$. 


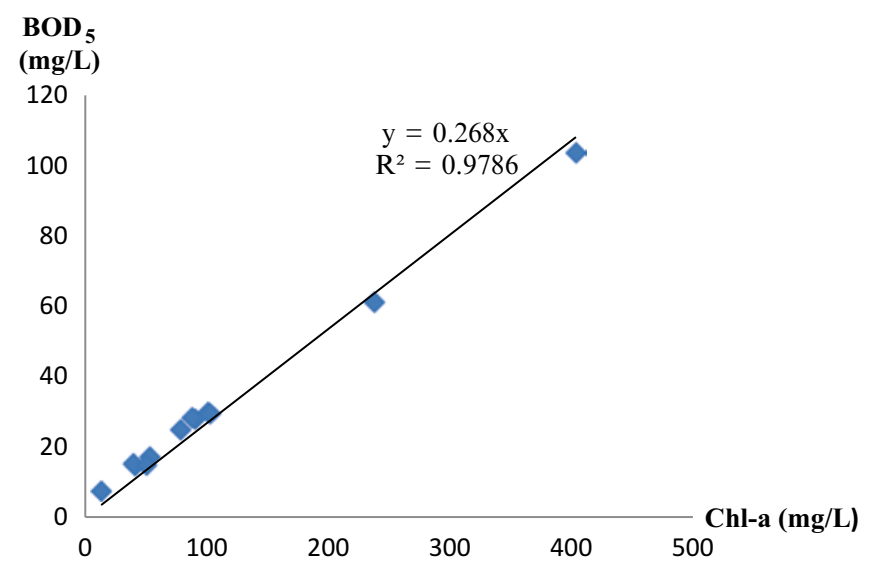

Fig. 15.12 Correlation between Chl-a and BOD in March 29 Park Lake

In both research subjects, there is a high linear correlation between the concentrations of Chl-a and BOD.

\subsubsection{Correlation Between Chl-a and Phosphate and Total Nitrogen}

Biological cycles of nitrogen and phosphorus occur in water as they do on land. However, due to the light attenuation and water stratification, biological processes that absorb and replicate nutrients occur differently by depth. The phenomenon of water stratification and seasonal changes varies in different climate zones. Stratification causes temperature changes and changes in the salinity of the water. When a water body is stratified, the exchange between surface and depths is very slight. The process of temperature change creates a significant barrier to the spread and transport of substances between two layers of water, so nutrients in the top layer can be depleted and limit algal productivity.

The study period was from March to May 2013, and samples were taken from approximately $30 \mathrm{~cm}$ below the water surface. The correlation charts are shown in Figs. 15.13 and 15.14.

The result of observation in the two lakes during three months in 2013 indicated no clear correlations between the parameters of phosphate or nitrogen content and of Chl-a. This result could have been affected by weather factors such as rain, the depth of sampling locations, and sunlight, which make algae either float on the water or sink. 


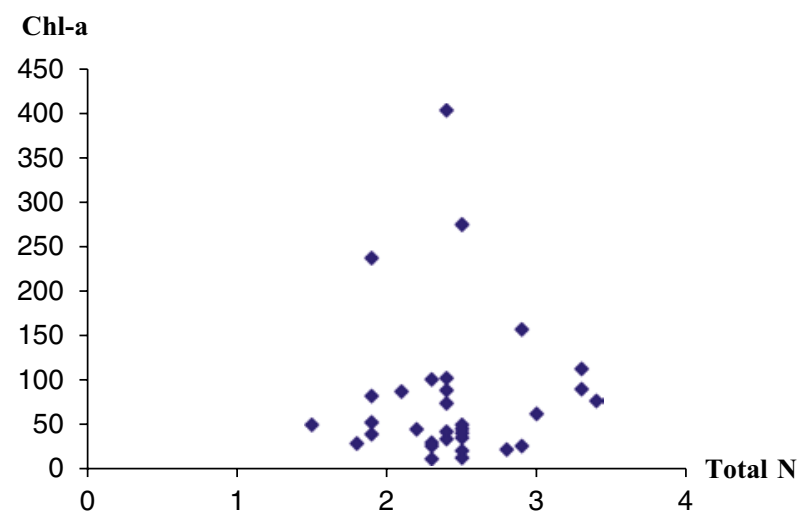

Fig. 15.13 Correlation between Chl-a and phosphate

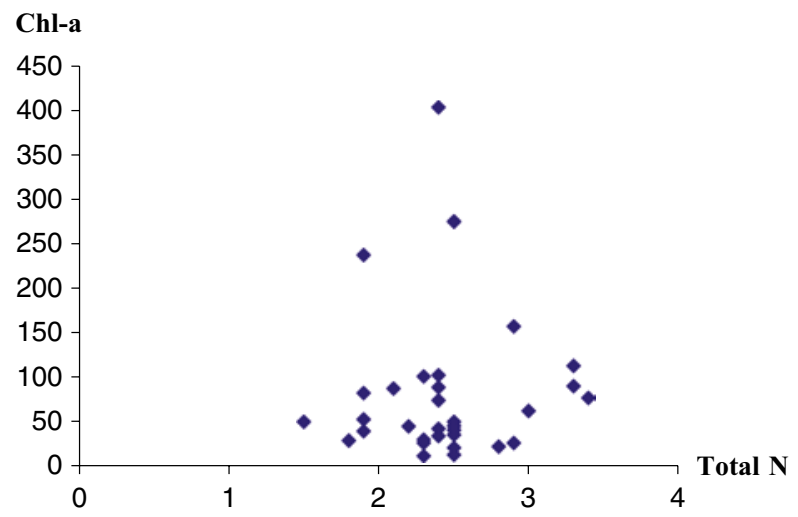

Fig. 15.14 Correlation between Chl-a and total nitrogen

\subsection{Conclusion}

Chl-a is an important parameter in water quality assessment, as the growth of phytoplankton depends significantly on the concentration of organic matter in the water. However, the research shows:

- No correlation between Chl-a and COD as is usually the case in standing surface water

- A clear linear correlation between Chl-a and BOD in both research subjects:

Ham Nghi Lake : Chl $\mathrm{a}=0.2848 \mathrm{x}+3.7344$ with $\mathrm{R}^{2}=0.955$

March 29Park Lake : Chl $\mathrm{a}=0.2435 \mathrm{x}+5.097$ with $\mathrm{R}^{2}=0.998$ 
- Phosphate and total nitrogen are two important factors directly affecting the development of algae and they are also causes of eutrophication. However, no correlation was found between $\mathrm{Chl}-\mathrm{a}$ and phosphate or total nitrogen during the research period (March-May 2013).

Management of water and water pollution is an important task within environmental risk management. Use of Chl-a as an ecological indicator to assess water quality is required in order to optimize the tools of water quality management, as well as to quickly detect and reduce the damage from environmental risk. It should be combined with modeling tools to forecast, monitor, and provide scenarios of environmental risk and global climate change.

\subsection{Research Orientation}

Further research is needed to:

- Investigate the relationship between Chl-a and nutrient parameters such as total nitrogen and phosphate over the long term and in more research subjects under comparable weather conditions (during the dry and wet seasons)

- Identify the impact of climate factors, weather, and seasonal variation on the nutrient content of the water body

- Study wider basins such as rivers with many contributing factors to find out the general relationships between Chl-a and the above parameters to apply to any watershed

- Develop research in unstable basins to forecast dispersion of pollution and the eutrophication process

- Examine the use of Chl-a as an environmental indicator to assess water quality

Open Access This article is distributed under the terms of the Creative Commons Attribution Noncommercial License which permits any noncommercial use, distribution, and reproduction in any medium, provided the original author(s) and source are credited. 